\title{
Divergent utilization patterns of grass fructan, inulin, and other nonfiber carbohydrates by ruminal microbes ${ }^{1}$
}

\author{
M. B. Hall ${ }^{2}$ and P. J. Weimer \\ US Dairy Forage Research Center, USDA-Agricultural Research Service, Madison, WI 53706
}

\begin{abstract}
Fructans are an important nonfiber carbohydrate in cool season grasses. Their fermentation by ruminal microbes is not well described, though such information is needed to understand their nutritional value to ruminants. Our objective was to compare kinetics and product formation of orchardgrass fructan (phlein; PHL) to other nonfiber carbohydrates when fermented in vitro with mixed or pure culture ruminal microbes. Studies were carried out as randomized complete block designs. All rates given are first-order rate constants. With mixed ruminal microbes, rate of substrate disappearance tended to be greater for glucose (GLC) than for PHL and chicory fructan (inulin; INU), which tended to differ from each other $(0.74,0.62$, and 0.33 $\mathrm{h}^{-1}$, respectively). Disappearance of GLC had almost no lag time $(0.04 \mathrm{~h})$, whereas the fructans had lags of $1.4 \mathrm{~h}$. The maximum microbial $\mathrm{N}$ accumulation, a proxy for cell growth, tended to be $20 \%$ greater for PHL and INU than for GLC. The N accumulation rate for GLC $\left(1.31 \mathrm{~h}^{-1}\right)$ was greater than for PHL $(0.75$ $\mathrm{h}^{-1}$ ) and INU $\left(0.26 \mathrm{~h}^{-1}\right)$, which also differed. More microbial glycogen $(+57 \%)$ was accumulated from GLC than from PHL, though accumulation rates did not differ (1.95 and $1.44 \mathrm{~h}^{-1}$, respectively); little glycogen accumulated from INU. Rates of organic acid formation were $0.80,0.28$, and $0.80 \mathrm{~h}^{-1}$ for GLC, INU, and PHL, respectively, with PHL tending to be greater than INU. Lactic acid production was more than 7 -fold greater for GLC than for the fructans. The ratio of microbial cell carbon to organic acid carbon tended to be greater for PHL (0.90) and INU (0.86) than for GLC (0.69), indicating a greater yield of cell mass per amount of substrate fermented with fructans. Reduced microbial yield for GLC may relate to the greater glycogen
\end{abstract}

Received September 17, 2015

Accepted September 29, 2015.

${ }^{1}$ Mention of any trademark or proprietary product in this paper does not constitute a guarantee or warranty of the product by the USDA or the Agricultural Research Service and does not imply its approval to the exclusion of other products that also may be suitable.

${ }^{2}$ Corresponding author: marybeth.hall@ars.usda.gov production that requires ATP, and lactate production that yields less ATP; together, these processes could have reduced ATP available for cell growth. Acetate molar proportion was less for GLC than for fructans, and less for PHL than for INU. In studies with pure cultures, all microbes evaluated showed differences in specific growth rate constants $(\mu)$ for GLC, fructose, sucrose, maltose, and PHL. Selenomonas ruminantium and Streptococcus bovis showed the highest $\mu$ for PHL (0.55 and $0.67 \mathrm{~h}^{-1}$, respectively), which were 50 to $60 \%$ of the $\mu$ achieved for GLC. The 10 other species tested had $\mu$ between 0.01 and $0.11 \mathrm{~h}^{-1}$ with PHL. Ruminal microbes use PHL differently than they do GLC or INU.

Key words: rumen, fermentation, fructan, nonfiber carbohydrate

\section{INTRODUCTION}

Fructan is the generic name for linear and branched polymers of D-fructose comprised primarily of fructose, but often containing a terminal glucose. These are nonstructural carbohydrates produced by many plants as an energy storage material, often ancillary to starch production (Hendry and Wallace, 1993). The bonding between the sugar molecules can differ by source, such as $\beta-(2,1)$ linkages predominating in chicory (Cichorium intybus) inulin and $\beta-(2,6)$ linkages in phlein of cool season grasses (e.g., Dactylis glomerata; Lewis, 1993). Among commonly used forages, fructans are found in cool season grasses. They may account for a small $(<1 \%$ of DM) or substantial ( $>20 \%$ of DM) portion of the nonfiber carbohydrate (Mackenzie and Wylam, 1957). Unlike the monosaccharides, sucrose, or starch, fructans are not digestible by mammalian enzymes, but are used by ruminal microbes. Thus, fructans can provide an important energy source for ruminal microbiota.

Relatively little has been done to characterize the fermentation of grass fructans by mixed ruminal microbes. Thomas (1960) found that Italian ryegrass (Lolium italicum) fructan was fermented to VFA and lactic acid, and was also converted to microbial glycogen by both protozoa and bacteria. The protozoal, and to a lesser 
extent, bacterial fractions of mixed ruminal microbes have been shown to possess $\beta$-fructofuranosidase (EC 3.2.1.26) activity (Czerkawski and Lumsden, 1971), and this activity has been demonstrated in 6 species of ruminal bacteria (Ziolecki et al., 1992). More recently, Piknova et al. (2008) described a new bacterial species, "Treponema zioleckii" that is capable of fermenting fructan from timothy (Phleum pratense), as well as pectin and several soluble sugars. However, little quantitative information is available regarding growth of ruminal microbes on fructan or overall fates of the substrate in short-term fermentations. Here we examine grass fructan as compared with other nonfiber carbohydrates as they affect fermentation kinetics and product formation of mixed ruminal microbiota in vitro, and specific growth rates among different individual species of ruminal bacteria. The mixed culture study was performed in vitro because the ruminal system in vivo is too complex to allow evaluation of the measures investigated.

\section{MATERIALS AND METHODS}

\section{Experiment 1. Mixed Culture Fermentations}

Substrates. Purified glucose (G7021, Sigma, St. Louis, MO), inulin from chicory (Orafti-HP, BENEO, GmbH, Mannheim, Germany), and purified phlein were used as substrates. Phlein isolated from orchardgrass (Dactylis glomerata) was a gift from P. Harrison, USDA-ARS Forage and Range Research Laboratory, Logan, Utah. The phlein was isolated using initial extractions with $80 \%$ ethanol to remove low molecular carbohydrates, water extraction to extract the phlein, then removal of coloring material and proteins from the water extract using anion exchange medium (diethylaminoethyl cellulose) and precipitation of protein using $\mathrm{ZnSO}_{4}$. The phlein was further purified to remove lower molecular weight carbohydrates through ultrafiltration under pressure with stirring (Amicon stirred cell model 8200, EMD Millipore, Darmstadt, Germany) using ultrafiltration discs with a nominal molecular weight cutoff of $1 \mathrm{kDa}$ (PLAC07610, EMD Millipore, Darmstadt, Germany). For ultrafiltration, solutions of the phlein in ultrapure water were stirred at $4^{\circ} \mathrm{C}$ under $\mathrm{N}_{2}$ gas at 193 $\mathrm{kPa}\left(28 \mathrm{lb} / \mathrm{in}^{2}\right)$.

Fermentations. Duplicate fermentation runs were performed using Goering and Van Soest (1970) medium in sealed borosilicate glass fermentation tubes $(121 \mathrm{~mm}$ long, $28 \mathrm{~mm}$ outer diameter, $2.8 \mathrm{~mm}$ wall thickness, the ends of the tubes were formed to be sealed with crown caps; custom made by Wilmad-LabGlass, Vineland, NJ). Each vessel contained $20 \mathrm{~mL}$ of medium, $1 \mathrm{~mL}$ of reducing solution, and $5 \mathrm{~mL}$ of ruminal inoculum. The medium plus reducing solution supplied $6.54 \mathrm{mg}$ of
$\mathrm{N}$ from tryptone (pancreatic digest of casein, T-9410, Sigma-Aldrich Co.), $3.54 \mathrm{mg}$ of $\mathrm{N}$ from ammonium bicarbonate, and $0.56 \mathrm{mg}$ of $\mathrm{N}$ from cysteine- $\mathrm{HCl}$ in each tube. Vessels were incubated in tube racks in an incubating orbital shaker at $39^{\circ} \mathrm{C}$ and $160 \mathrm{rpm}$ (Innova 40 bench top incubator shaker, $19 \mathrm{~mm}$ orbit, New Brunswick Scientific, Edison, NJ). Tubes were secured within racks which were set on their sides within the incubator so that the long axis of the tubes was positioned parallel to the platform and motion of the shaker to continuously mix substrate, inoculum, and medium. Glucose, inulin, and phlein substrates (78 $\mathrm{mg}$ of DM per tube, SD of sample weights $=0.3 \mathrm{mg}$ ) were weighed into 3 replicate vessels each for each sampling time after $0 \mathrm{~h}$. The replicates were used for analysis of accumulated microbial N, glycogen, and organic acids/residual carbohydrate; 3 pairs of tubes with no substrate (fermentation blanks) collected at $0 \mathrm{~h}$ were subject to the same 3 analyses. Two fermentation blanks were included at each time point for organic acid/residual carbohydrate analysis. Fermentation runs were performed 1 yr apart.

Inoculum for each fermentation was obtained from 2 lactating Holstein cows maintained under protocols approved by the University of Wisconsin College of Agriculture and Life Sciences Animal Care and Use Committee. In the 2 separate years, donor cows were fed a TMR consisting on a DM basis of 25 to $29 \%$ corn silage, 19 to $24 \%$ alfalfa haylage, $6 \%$ whole linted cottonseed, and 44 to $45 \%$ mixed concentrate supplemented with vitamins and minerals to meet NRC (2001) recommendations; in the second year, $1 \%$ wheat straw was included in the diet. For each cow in each year, $50 \mathrm{~g}$ of inulin (Orafti-HP) and $50 \mathrm{~g}$ of dextrose were mixed into the TMR and the diet was top-dressed with $\sim 0.1 \mathrm{~kg}$ of timothy (Phleum pratense) hay in the $15 \mathrm{~d}$ before inoculum collection. Ruminal contents obtained from each cow within $2 \mathrm{~h}$ postfeeding were strained through 4 layers of cheesecloth and the ruminal liquor maintained under $\mathrm{CO}_{2}$. Equal volumes of ruminal liquor from each cow were measured and filtered through an additional 4 layers of cheesecloth with ruminal fluid from both cows blended together in a common flask maintained at $39^{\circ} \mathrm{C}$ in a water bath with $\mathrm{CO}_{2}$ bubbled continuously through the liquor. Inocula $\mathrm{pH}$ values in the fermentation runs were 5.98 and 5.73 , which were approximately the average ruminal digesta $\mathrm{pH}$ of the 2 cows used in each run.

Fermentation vessels were destructively sampled at 0 , $0.25,0.50,0.75,1,1.5,2,3,4,6$, and $8 \mathrm{~h}$, except for the phlein substrates for which 0.5 and $1.5 \mathrm{~h}$ time points were omitted due to limitations in amount of available substrate. At each sampling hour, harvested tubes were placed immediately on ice and chilled for a minimum of $10 \mathrm{~min}$ to stop the fermentation. One tube for each 
substrate and 2 fermentation blanks were uncapped just before $\mathrm{pH}$ was measured; $\mathrm{pH}$ did not decline below 6.43 in any vessel. Total contents of each of these tubes were divided between two $20-\mathrm{mL}$ scintillation vials and stored at $-20^{\circ} \mathrm{C}$ until analyzed for organic acids, and residual soluble carbohydrate.

Microbially accumulated $\mathrm{N}$ was analyzed with a modification of the procedure used in Hall (2011). In the present study, initial, lower $g$-force centrifugations and an excess of formalin were used to help ensure preservation of the protozoa and their contents for $\mathrm{N}$ analysis. In the Hall (2011) study, loss of cell contents was considered a possible basis for the $<100 \%$ carbon balance estimated if $\mathrm{AA}$ in the medium were incorporated into the cells. Gas pressure was released from samples destined for accumulated $\mathrm{N}$ analysis ( 1 tube for each substrate at each sampling hour $>0$ h, 2 fermentation blanks at $0 \mathrm{~h}$ ) and samples were centrifuged in the fermentation tubes at $1,000 \times g$ for $10 \mathrm{~min}$ at ambient temperature. Supernatant was decanted into high-speed centrifuge tubes (\#361694, Beckman Coulter Inc., Brea, CA). A $37 \%$ formaldehyde solution (1 mL; no. 410730010, Acros Organics, Waltham, MA) was added to each pellet, swirled to mix, the interior of the tube rinsed with $0.9 \% \mathrm{NaCl}$, and the tubes again centrifuged at $1,000 \times g$ for $10 \mathrm{~min}$ at ambient temperature. Supernatant was decanted into the high-speed centrifuge tubes with the initial supernatant, and centrifuged at $13,000 \times g$ for $45 \mathrm{~min}$ at $5^{\circ} \mathrm{C}$. Supernatant was decanted and discarded, the pellet was resuspended in $0.9 \% \mathrm{NaCl}$, and centrifuged at $13,000 \times g$ for $45 \mathrm{~min}$ at $5^{\circ} \mathrm{C}$. The supernatant was discarded. Pellets from low-speed and high-speed centrifugations for a sample were quantitatively transferred using $0.9 \% \mathrm{NaCl}$ to a single $50-\mathrm{mL}$ screw-cap conical tube, then were frozen at $-20^{\circ} \mathrm{C}$ and lyophilized.

Entire contents of fermentation tubes used for $\alpha$-glucan and glycogen analysis ( 1 tube for each substrate at each sampling hour $>0 \mathrm{~h}, 2$ fermentation blanks at $0 \mathrm{~h}$ ) were transferred quantitatively with $0.9 \% \mathrm{NaCl}$ rinses to 50-mL high-speed centrifuge tubes (\#361694, Beckman Coulter Inc., Brea, CA) and centrifuged at 13,000 $\times$ $g$ for $45 \mathrm{~min}$ at $5^{\circ} \mathrm{C}$. The supernatant was decanted and discarded. Pellets which contained the microbial cells were resuspended in $0.9 \% \mathrm{NaCl}$, and centrifuged at $13,000 \times g$ for $45 \mathrm{~min}$ at $5^{\circ} \mathrm{C}$. The supernatant was discarded. The pellet was quantitatively transferred using $0.2 \mathrm{M} \mathrm{NaOH}$ (approximately 15 to $20 \mathrm{~mL}$ ) to $50-\mathrm{mL}$ beakers, which were frozen at $-20^{\circ} \mathrm{C}$ until analysis.

Analyses. Lyophilized fermentation pellets were analyzed for N (Dumas combustion method, VarioMax CN, Elementar Americas Inc., Mt. Laurel, NJ). Nitrogen accreted by microbes was calculated as the hourly sample values minus the average value of the 0 -h fer- mentation blanks to correct for $\mathrm{N}$ introduced with the inoculum. Organic acid concentrations in samples of medium were analyzed by HPLC (Weimer et al., 1991). Values for organic acids were corrected for the average of the fermentation blanks for the sampling hour. Total organic acid values are the sum of acetate, propionate, butyrate, valerate, and lactate; for total VFA, lactate was omitted. Production of $\mathrm{CH}_{4}$ and $\mathrm{CO}_{2}$ were estimated from organic acid production according to the stoichiometric equations of Hungate (1966). These equations assume that no organic acid was produced from substrates other than carbohydrate.

Accumulated glycogen $\alpha$-glucan was performed as described by Hall (2011) for microbial samples lysed by boiling for $15 \mathrm{~min}$ with $0.2 \mathrm{M} \mathrm{NaOH}$ (Chen and Russell, 1988), an assay that is a modification of the alkali-enzymatic method of Becker (1978). For analysis, the glycogen was not isolated from the microbes, but the microbial cells were lysed with alkali to allow access of the $\alpha$-amylase and amyloglucosidase to hydrolyze the glycogen to glucose. $\alpha$-Glucan or glycogen was calculated as detected glucose $\times 0.9$. Net accumulated glycogen was calculated as hourly sample values minus the average value of the $0-\mathrm{h}$ fermentation blanks. The 0 -h fermentation blank allowed correction for $\alpha$-glucan from microbes or undigested feed introduced by the ruminal inoculum.

Residual carbohydrate soluble in the medium was analyzed with the phenol-sulfuric acid assay (Dubois et al., 1956), halving all volumes per tube $(0.5 \mathrm{~mL}$ of $5 \%$ phenol solution, $0.5 \mathrm{~mL}$ of samples solution, and $2.5 \mathrm{~mL}$ of concentrated sulfuric acid), and with vortexing of samples performed after each reagent addition except the first. Samples including fermentation blanks were thawed at room temperature, inverted to mix, and approximately $1.5 \mathrm{~mL}$ transferred to a $2-\mathrm{mL}$ microcentrifuge tube. Samples were incubated at $60^{\circ} \mathrm{C}$ for $20 \mathrm{~min}$ in a recirculating water bath to completely solubilize all residual soluble carbohydrate; failure to perform this incubation resulted in reduced recoveries for the fructan samples at early time points (data not shown). The tubes were inverted to mix, centrifuged at $12,000 \times g$ for $10 \mathrm{~min}$ at ambient temperature, and then allowed to sit on the bench for 5 to $10 \mathrm{~min}$ for temperature equilibration. Samples of the clarified supernatant were diluted with distilled water as needed and analyzed for carbohydrate (Dubois et al., 1956). Glucose was used as the standard for samples in which glucose was the fermentation substrate, and inulin (Orafti-HP) when inulin or phlein were the substrates. The amount of carbohydrate soluble in the medium was measured in the fermentation blanks using both glucose and inulin as standards. For each fermentation hour, a fermentation blank value for that hour was subtracted 
from values for samples analyzed with the same carbohydrate standard.

Calculations. Micromoles of organic acids were calculated as the millimolar concentration of an acid $x$ $0.026 \mathrm{~L} \times 1,000 \mu \mathrm{mol} / \mathrm{mmol}$. Carbon in organic acids was calculated as $2,3,3,4$, and 5 micromoles of $\mathrm{C}$ per micromole of acetate, propionate, lactate, butyrate, and valerate, respectively. Total micromoles of $\mathrm{C}$ in organic acids per sample vessel was calculated as the sum of the values for the 5 organic acids; for the sum of $\mathrm{C}$ in VFA, the value for lactate was omitted. Micromoles of nonglycogen microbial cell $\mathrm{C}$ was estimated as accumulated microbial $\mathrm{N}, \mathrm{mg} /(14 \mathrm{mg} / \mathrm{N} \mathrm{mmol}) \times$ $(5 \mathrm{C} / 1 \mathrm{~N}) \times(1,000 \mu \mathrm{mol} / \mathrm{mmol})$. This calculation is based on the report of Pavlostathis et al. (1988) who described an average, chemical composition of nonglycogen microbial cell mass as $\mathrm{C}_{5} \mathrm{H}_{7} \mathrm{O}_{2} \mathrm{~N}$ (excluding ash). Carbon in glycogen and in $\alpha$-glucan introduced with the inoculum were calculated as $\alpha$-glucan or glycogen $\mathrm{mg} \times 0.44 \times(\mathrm{C} \mathrm{mmol} / 12 \mathrm{mg}$ of $\mathrm{C}) \times(1,000 \mu \mathrm{mol} /$ $\mathrm{mmol}) ; 0.44$ represents the proportion of $\mathrm{C}$ in $\alpha$-glucan. For all substrates, micromoles were converted to milligrams of $\mathrm{C}$ by multiplying micromole amounts by $(12 \mathrm{mg} \mathrm{C} / \mathrm{mmol} \mathrm{C}) /(1,000 \mu \mathrm{mol} / \mathrm{mmol})$. Calculations of the $\mathrm{C}$ contribution of incorporated preformed AA, and peptides from the medium were calculated as accumulated $\mathrm{N} \mathrm{mg} \times 6.25 \times 0.615 \times 0.85 \times 0.51$, where 6.25 is for the conversion of $\mathrm{N}$ to $\mathrm{CP}, 0.615$ represents the proportion of $\mathrm{N}$ incorporated into ruminal microbes supplied with glucose that did not come from ammonia (Hristov et al., 2005), 0.85 is the proportion of microbial $\mathrm{N}$ estimated to be true protein ( 0.15 from nucleic acids, Russell et al., 1992), and 0.51 is the average proportion of $\mathrm{C}$ in $\mathrm{AA}$.

Lag times and exponential rates for organic acid production, increasing microbial accumulation of $\mathrm{N}$ and glycogen, and disappearance of substrate were calculated using single pool exponential equations (Weimer et al., 2000). For calculations with accumulated microbial $\mathrm{N}$, data after the detected maximum were omitted. The glycogen data were split into 2 sections: the increasing part of the curve to the detected maximum (i.e., period of net glycogen accumulation), and the decreasing part of the curve from the maximum value through $8 \mathrm{~h}$ sample (i.e., period of net glycogen consumption). The rate of glycogen decay was calculated using a single pool exponential equation with no lag. All rate calculations were performed using TableCurve 2D Version 5.01 (Systat Software Inc., San Jose, CA).

Statistical Analysis. References to "maxima" or "maximum" values refer to the greatest value detected for a particular analyte in a fermentation run. The data were analyzed as a randomized complete block design. Exponential rates and lag times, maximum values, and values for microbial products and efficiency at the time of maximum microbial $\mathrm{N}$ accumulation were analyzed according to a model with "substrate" as a fixed independent variable, and "fermentation run" as a random variable. Analysis of accumulated cell $\mathrm{C}$ /organic acid $\mathrm{C}(\mu \mathrm{mol} / \mu \mathrm{mol})$ was analyzed by a model that included "substrate" as a fixed independent variable, "sampling time" as a continuous variable, the interaction of time and substrate, and "fermentation run" as a random variable. The range of data used for each substrate in each fermentation for this analysis was that from the nonzero sampling time closest to the lag time predicted for organic acid production to the time of maximum microbial N. Orthogonal contrasts comparing glucose versus inulin and phlein, and inulin versus phlein, were used. These analyses were performed using the MIXED procedure of SAS (version 9.3, SAS Institute Inc., Cary, NC). Pearson correlation coefficients among maxima for microbial products were determined using the CORR procedure of SAS. $t$-Tests were performed by fermentation run by substrate on the differences across all time points between $\mathrm{C}$ in microbial products and the sum of $\mathrm{C}$ in utilized substrate and $\alpha$-glucan introduced with the inoculum with or without adjustment for C contributed by AA in the medium. The test evaluated whether the difference between product and substrate differed from zero. Values are reported as least squares means with standard errors of the difference. Significance was declared at $P<0.05$, and tendencies at 0.05 $\leq P<0.15$.

\section{Experiment 2. Pure Culture Fermentations}

Substrates. Phlein (fructan from orchardgrass, Dactylis glomerata) was a gift from P. Harrison, USDA-Agricultural Research Service Forage and Range Research Laboratory, Logan, Utah. Although predominantly polymeric, the carbohydrate consisted of $17.2 \mathrm{~g} / \mathrm{kg}$ of mono- and oligosaccharides, distributed as follows (g/ $\mathrm{kg}$ each): glucose, 1.46; fructose, 0.99; sucrose, 6.42 ; raffinose, 2.95; 1-kestose, 0.49; 6-kestose, 0.40; 1-nystose, 0.80 ; 6-nystose, 0.29 ; and bifurcose, 0.75 , as measured by anion exchange chromatography with pulsed amperometric detection (Ernst et al., 1998). Other carbohydrates and chemicals used in this study were reagent grade, from Sigma-Aldrich (St. Louis, MO).

Microbial Inocula. Pure bacterial cultures were revived from frozen $\left(-80^{\circ} \mathrm{C}\right) 50 \%$ glycerol stocks by transfer of $0.2 \mathrm{~mL}$ of thawed stock into $10 \mathrm{~mL}$ of modified Dehority medium (MDM, Weimer et al., 1991) containing $5 \mathrm{~g}$ of glucose and $1 \mathrm{~g}$ yeast extract/L, followed by overnight incubation at $39^{\circ} \mathrm{C}$.

Pure Culture Fermentations. Growth rates of pure cultures were determined in 96-well microtiter 
plates (BD Falcon, BD Biosciences, Billerica, MA) incubated in an anaerobic glovebag, as described previously (Weimer and Abrams, 2001). The glovebag fill gas was $50 \% \mathrm{CO}_{2}, 40 \% \mathrm{~N}_{2}$, and $10 \% \mathrm{H}_{2}$ by volume, and $\mathrm{H}_{2}$ concentration in the glovebag was typically $\sim 2 \%$ by volume. Individual wells of the microtiter plate contained $270 \mu \mathrm{L}$ of MDM supplemented with fructan or other carbohydrate source $(10 \mathrm{~g} / \mathrm{L})$ and yeast extract $(2 \mathrm{~g} / \mathrm{L})$, and were inoculated with $30 \mu \mathrm{L}$ of a 6 -fold dilution of an exponential-phase pure culture grown on MDM plus $5 \mathrm{~g}$ of fructose/L. Control wells contained either the same medium without added carbohydrate (for background correction of optical density), or 300 $\mu \mathrm{L}$ of the same medium, but without inoculum (as a contamination check). Plates were incubated at $39^{\circ} \mathrm{C}$ in a model 808-I plate reader (Bio-Tek Instruments, Winooski, VT) inside the glovebag. KC4 software (Bio-Tek Instruments) was used to control incubation conditions and to collect optical density data. Plates were automatically shaken at maximum intensity for $15 \mathrm{~s}$ before each optical density $\left(600 \mathrm{~nm} ; \mathbf{O D}_{600}\right)$ reading. Depending on the individual cultures, $\mathrm{OD}_{600}$ reading intervals ranged from 5 to $20 \mathrm{~min}$, and run times varied from 16 to $40 \mathrm{~h}$. Growth rates were determined from 6 replicate wells per treatment (strain $\times$ substrate combination), as the slope of the linear region of a plot of $\ln \mathrm{OD}_{600}$ versus time. Growth rates across substrates within bacterial strain were compared using the General Linear Model of SAS (SAS Institute, Cary, NC), after removal of occasional outliers using Dixon's Q-test (Rorabacher, 1991).

\section{RESULTS AND DISCUSSION}

\section{Experiment 1. Mixed Culture Fermentation}

The carbohydrates evaluated showed similarities and differences in their fermentation characteristics. Of particular interest were the differences between the 2 fructan sources.

Carbon Recovery. The recovery of substrate C used in products is shown in Figure 1. Substrate calculated as that provided by both experimental substrates and utilized $\alpha$-glucan introduced with the inoculum are shown in Figure 1a. In this scenario, the amount of $\mathrm{C}$ in products minus $\mathrm{C}$ in substrates in replicate fermentations (ferm) did not differ from 0 for glucose (ferm 1: $P=0.63$; ferm 2: $P=0.42$ ), approximating a $100 \% \mathrm{C}$ recovery. The pattern of product versus substrate $\mathrm{C}$ for glucose is similar to that reported by Hackmann et al. (2013, Figure 5f) with washed cells in N limited cultures. In that study the initial and final $\mathrm{C}$ recoveries were below $100 \%$, greater than $100 \%$ in the middle of the fermentation, but averaging $100 \%$ over the entire fermentation. In our study, the differences between product and substrate $\mathrm{C}$ were greater than 0 for both inulin (ferm 1: $P<0.01$ ferm 2: $P=0.03$ ) and phlein (ferm 1: $P<0.01$; ferm 2: $P=0.01$ ). This would mean that more product $\mathrm{C}$ was produced than substrate $\mathrm{C}$ consumed, which is infeasible. For inulin and phlein, the results may be a function of incorporation of AA from the medium with greater production of microbes, or of
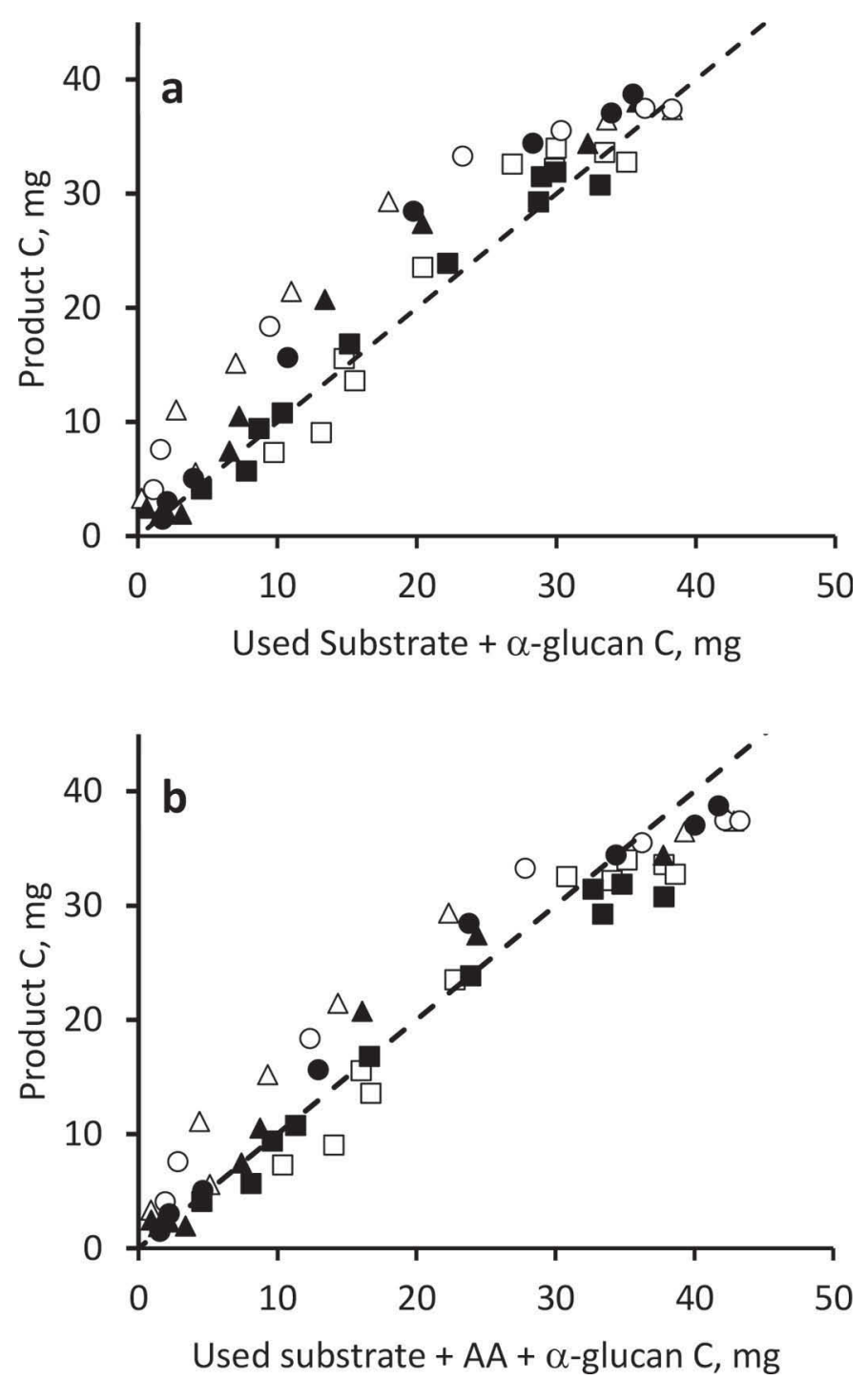

Figure 1. Amount of carbon in utilized substrates and in microbial products for individual substrates in each fermentation. Substrates in (a) include glucose, inulin, phlein, and $\alpha$-glucan introduced with the inoculum that was used; (b) also includes carbon provided by AA in the medium estimating that all accumulated microbial AA was provided by medium AA. The dashed unity line describes utilized substrate carbon $=$ carbon in products. Products include microbial cells, organic acids, carbon dioxide and methane, and accumulated glycogen. Substrates: glucose $=\square, \boldsymbol{\square}$, phlein $=\bigcirc, \boldsymbol{\bullet}$, and inulin $=\Delta$, $\mathbf{\Delta}$; open symbols are from fermentation 1, closed symbols from fermentation 2 . 
some effect on contribution of $\mathrm{C}$ from other fermented substrates such as NDF introduced with the inoculum.

When utilized substrate values were adjusted for the contribution of $\mathrm{C}$ from $\mathrm{AA}$ in the medium as providing all AA estimated to be accumulated by the microbes, the $\mathrm{C}$ balance did not differ from 0 for inulin (ferm 1: $P=0.38$; ferm 2: $P=0.36$ ) and phlein (ferm 1: $P$ $=0.83$; ferm $2: P=0.24)$, but declined below 0 for glucose (ferm 1: $P<0.01$; ferm 2: $P=0.01$; Figure 1b). The average of replicate fermentations for mean differences between $\mathrm{C}$ in products and utilized substrate $\mathrm{C}$, divided by the mean substrate $\mathrm{C}$ utilized were 2,31 , and $26 \%$ without including potential AA contributions, and $-9,12$, and $5 \%$ with AA contributions for glucose, inulin, and phlein, respectively. Although inclusion of estimated AA contributions brought overall C recovery values closer to $100 \%$ for inulin and phlein, it worsened the situation for glucose.

It is probable that neither evaluation of $\mathrm{C}$ recovery is correct. Some partial contribution of medium AA to microbial AA is likely, but it is also likely that other components of the inoculum may contribute $\mathrm{C}$, as well as microbial products that are not measured (e.g., exopolysaccharides and degraded microbial cells). The C contributors and products may differ by substrate and by the microbes using the substrates, perhaps due to differences in metabolic status of cells growing at different rates. Accuracy of detection methods, calculations, and assumptions will also affect accuracy of $\mathrm{C}$ recovery estimates. The mean and $95 \%$ confidence interval bounds from the $t$-tests of product $\mathrm{C}(\mathrm{mg})$ minus substrate C (mg) with no credit for medium AA contribution in each fermentation were as follows: glucose, ferm $1,0.51,-1.80,2.82$, ferm $2,0.44,-0.75,1.63$; inulin, ferm $1,5.39,2.33,8.46$, ferm $2,2.35,0.35,4.35$; and phlein, ferm 1, 5.02, 1.87, 8.17, ferm 2, 3.44, 0.94, 5.95 . The mean and $95 \%$ confidence interval bounds when all estimated microbial AA accumulation was attributed to incorporation of preformed AA from medium were as follows: glucose, ferm $1,-3.98,-5.79,-2.18$, ferm 2 , $-3.36,-5.71,-1.02$; inulin, ferm $1,1.52,-2.16,5.19$, ferm $2,-1.10,-3.68,1.48$; and phlein, ferm $1,-0.46$, $-5.41,4.48$, ferm $2,-1.64,-4.70,1.41$.

Substrate Disappearance. Glucose disappearance had a shorter lag time $(P<0.01)$ than did the disappearance of the fructans, which did not differ from each other $(P=0.78$; Table 1 , Figure 2a). The rates of substrate disappearance tended to be more rapid for glucose than for fructans $(P=0.11)$, and a tendency was observed for phlein to disappear more rapidly than inulin $(P=0.12)$. Thomas (1960) had reported more rapid in vitro disappearance of monosaccharide fructose and disaccharide sucrose than for grass fructan with ruminal inoculum containing both protozoa and bacteria. When inoculum from a defaunated sheep was used, the 3 carbohydrates disappeared at similar rates. Differences in the rate of disappearance of different fructans in ruminal fluid from a cow was demonstrated by Biggs and Hancock (1998) with microbial fructan (levan) disappearing more slowly than inulin. Both fructans disappeared more slowly than fructose.

Glycogen. Maximal glycogen accumulation was greatest with glucose $(P<0.01)$ and greater for phlein than for inulin $(P<0.01$; Table 2 , Figure $2 \mathrm{~b})$, with maximum glycogen accumulation observed at 2,4 , and $3 \mathrm{~h}$ of fermentation, respectively. A casual observation made during both fermentation runs was the presence of visibly more white sediment in fermentation tubes containing glucose, a much smaller amount with phlein, and almost none with inulin. As reported previously,

Table 1. Exponential rate constants (kd) and lag times for experiment 1

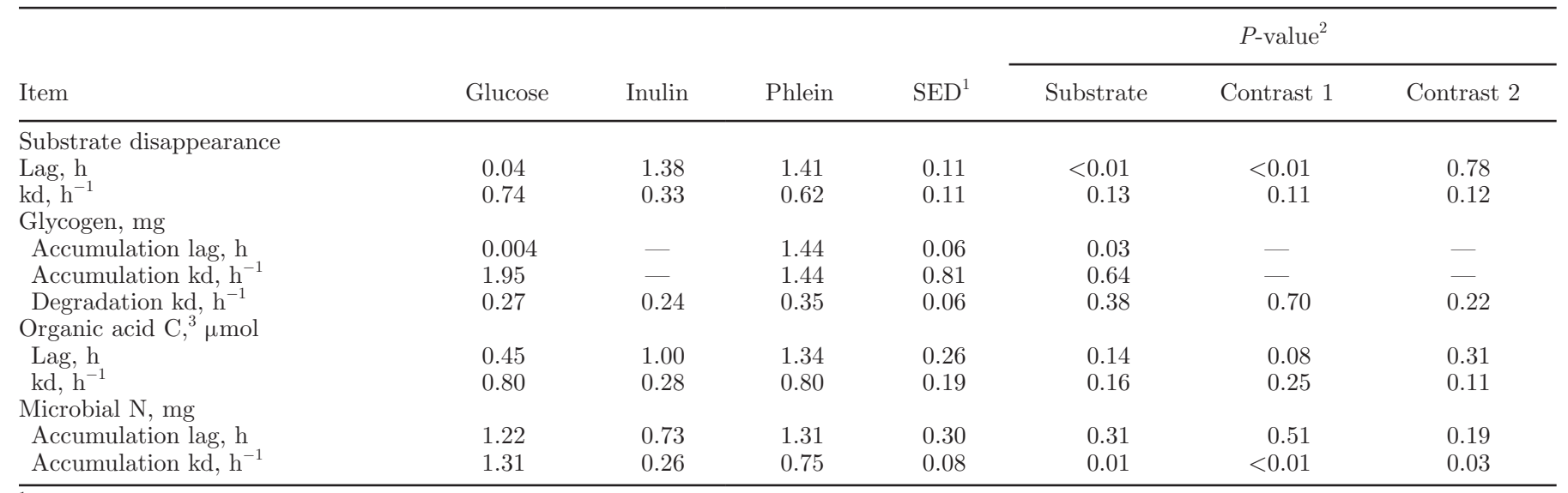

${ }^{1} \mathrm{SED}=$ standard error of the difference.

${ }^{2}$ Contrast $1=$ glucose vs. inulin + phlein, contrast $2=$ inulin vs. phlein.

${ }^{3}$ Organic acids $=$ acetate + propionate + butyrate + valerate + lactate. 

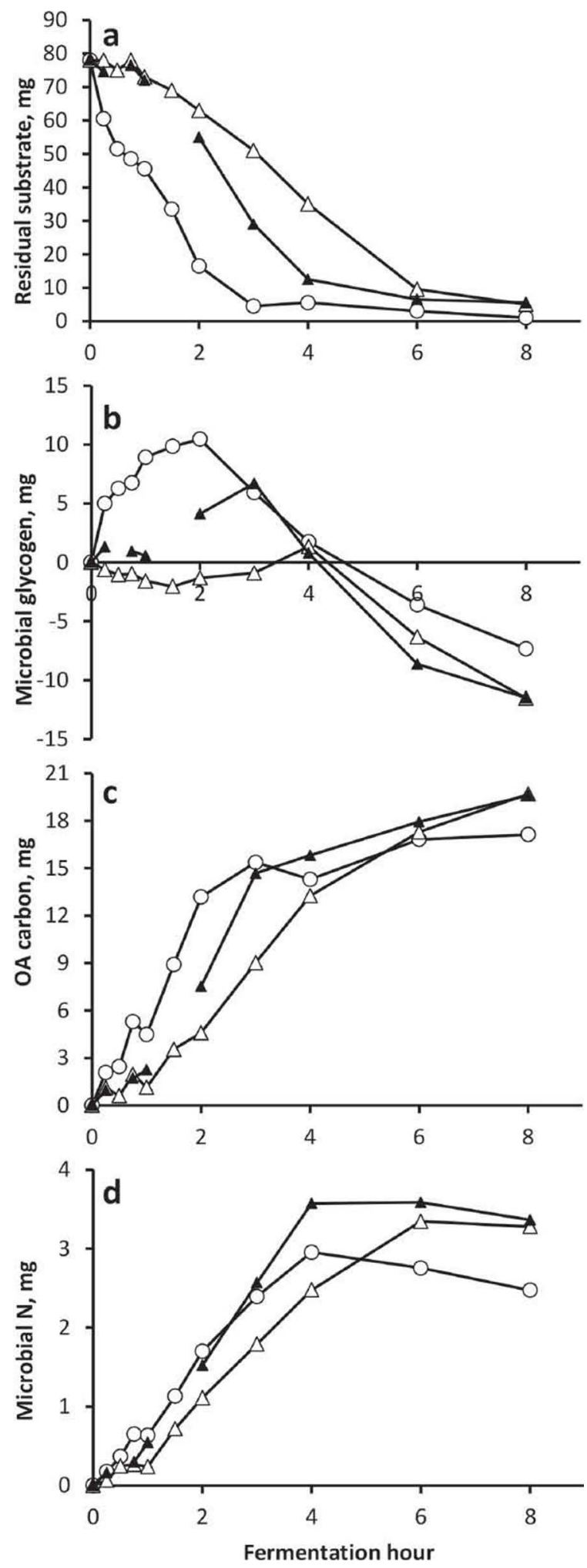

Figure 2. Patterns of substrate disappearance and microbial product appearance over time for mixed cultures (experiment 1). a $=$ residual added substrate, $\mathrm{b}=$ net accumulation of microbial glycogen, $\mathrm{c}$ $=$ organic acids $(\mathrm{OA}$; acetate + propionate + butyrate + valerate + lactate), and $\mathrm{d}=$ net accumulation of microbial N. Substrates: glucose $=\bigcirc$, phlein $=\boldsymbol{\Delta}$, and inulin $=\Delta$. the white sediment consists of isotrichid protozoa engorged with glycogen granules (Masson and Oxford, 1951; Hall, 2011). Although they may die out in longer term fermentations, ruminal protozoa are commonly present in short-term in vitro fermentations with soluble carbohydrate substrates and with inoculum prepared as described in the present study (M. B. Hall, unpublished). Maximum glycogen accumulation tended to be negatively correlated with maximum organic acid $\mathrm{C}(P=0.07)$ and with acetate molar percentage $(P=$ 0.07 ; Table 3$)$. Rates of glycogen accumulation were more than $1.0 \mathrm{~h}^{-1}$ and did not differ between glucose and phlein $(P=0.64)$, though the lag times differed substantially $(P=0.03$; Table 1$)$. Net glycogen accumulation ceased and decay predominated when the amount of residual hexose in the medium dropped below approximately $0.5 \mathrm{~g} / \mathrm{L}$. Rates of glycogen decay ranged from 0.24 to $0.35 \mathrm{~h}^{-1}$ and did not differ among substrates $(P>0.21$; Table 1$)$. These values are similar to the $0.23 \mathrm{~h}^{-1}$ degradation rate reported by Van Kessel and Russell (1997) for ruminal bacteria. Because sample values were corrected for $\alpha$-glucan contributed by the inoculum at $0 \mathrm{~h}$, the decline of the glycogen curves below $0 \mathrm{mg}$ reflect use of the glycogen and dietary starch brought in with the inoculum (an average of 17.3 and $12.2 \mathrm{mg}$ of $\alpha$-glucan introduced per tube at $0 \mathrm{~h}$ in the separate fermentation runs).

The flat form of the glycogen accumulation curve for inulin precluded calculation of exponential rates and lag times. However, the relatively flat curve with almost no net glycogen accumulation did not mean that glycogen was not being produced. Glycogen has been reported to be simultaneously synthesized and degraded (Prins and Van Hoven, 1977; Matheron et al., 1998). The flat form of the curve before obvious decay likely reflects a rate of glycogen synthesis approximately equal to the rate of glycogen degradation.

Several methods are available for analysis of glycogen in microbial cells, but they are not equally suitable for application to fermentation pellets produced with strained ruminal fluid. Unlike washed cells or pure cultures of microbes, such fermentation pellets contain residual feed particles that were introduced with the inoculum, and are nonhomogeneous with sedimenting protozoa and feed intermixed with the microbial mass; thus, they defy accurate subsampling. The nonhomogeneity necessitates the analysis of the entire fermentation pellet obtained from a given fermentation vessel. The size of the fermentation pellets produced in the present study's fermentation system (e.g., $1.2 \mathrm{~g}$ of wet weight at $2 \mathrm{~h}$ of fermentation when using glucose at 3 g/L; Hall and Hatfield, 2015) makes it infeasible to use glycogen methods that involve bead beating to lyse the microbes to liberate glycogen for analysis (Hackmann 
Table 2. Detected maxima for microbial products in experiment 1

\begin{tabular}{|c|c|c|c|c|c|c|c|}
\hline \multirow[b]{2}{*}{ Item } & \multirow[b]{2}{*}{ Glucose } & \multirow[b]{2}{*}{ Inulin } & \multirow[b]{2}{*}{ Phlein } & \multirow[b]{2}{*}{$\mathrm{SED}^{1}$} & \multicolumn{3}{|c|}{$P$-value ${ }^{2}$} \\
\hline & & & & & Substrate & Contrast 1 & Contrast 2 \\
\hline Glycogen, ${ }^{3} \mathrm{mg}$ & 10.5 & 1.3 & 6.7 & 0.36 & $<0.01$ & $<0.01$ & $<0.01$ \\
\hline Microbial $\mathrm{N},{ }^{4} \mathrm{mg}$ & 3.00 & 3.62 & 3.64 & 0.22 & 0.16 & 0.08 & 0.96 \\
\hline Lactate, $\mu \mathrm{mol}$ & 56.4 & 2.1 & 7.4 & 18.4 & 0.16 & 0.08 & 0.80 \\
\hline Organic acid $\mathrm{C},{ }^{5} \mu \mathrm{mol}$ & 1,442 & 1,641 & 1,635 & 69.0 & 0.16 & 0.08 & 0.93 \\
\hline Acetate, $\mathrm{mol} \%$ & 41.4 & 46.0 & 43.0 & 0.49 & 0.02 & 0.02 & 0.03 \\
\hline Propionate, $\mathrm{mol} \%$ & 42.9 & 41.7 & 42.2 & 1.55 & 0.77 & 0.56 & 0.77 \\
\hline Butyrate, mol\% & 14.4 & 11.4 & 13.9 & 1.66 & 0.35 & 0.36 & 0.27 \\
\hline Valerate, $\mathrm{mol} \%$ & 1.4 & 0.9 & 0.8 & 0.49 & 0.58 & 0.35 & 0.91 \\
\hline
\end{tabular}

${ }^{1} \mathrm{SED}=$ standard error of the difference.

${ }^{2}$ Contrast $1=$ glucose vs. inulin + phlein; contrast $2=$ inulin vs. phlein.

${ }^{3}$ Original glycogen values were corrected for 17.3 or $12.2 \mathrm{mg}$ of $\alpha$-glucan introduced with the inoculum in the separate fermentation runs.

${ }^{4}$ Original $\mathrm{N}$ values were corrected for 7.44 or $5.46 \mathrm{mg}$ of $\mathrm{N}$ introduced with the inoculum in the separate fermentation runs.

${ }^{5}$ Organic acids $=$ acetate + propionate + butyrate + valerate + lactate.

et al., 2013). An historical and recommended method for microbial glycogen analysis employs boiling subsampled cells in $30 \% \mathrm{KOH}$ for $3 \mathrm{~h}$ followed by isolation of glycogen and analysis with anthrone (Herbert et al., 1971; Daniels et al., 2007). The anthrone assay is a broad-spectrum carbohydrate assay that does not differentiate between $\alpha$-glucan and other carbohydrates. In addition to microbial glycogen, the anthrone assay detects carbohydrates in microbial cell walls (T. J. Hackmann, University of Florida, Gainesville, personal communication), microbial capsular polysaccharides that can contaminate even isolated glycogen (Daniels et al., 2007), and feed carbohydrates present in strained ruminal inoculum. Because the anthrone assay cannot differentiate among the diverse carbohydrates present and inseparable in the samples, it was not appropriate to use with the fermentation pellets in the present study. Use of enzymatic hydrolysis with amylolytic enzymes and specific detection of glucose is more specific for measurement of glycogen and other $\alpha$-glucans. The glycogen method used in the present study detected microbial glycogen in fermentation pellets produced with strained ruminal inoculum with values equivalent to those from processing/lysing the pellets by boiling them with $30 \% \mathrm{KOH}$ for $3 \mathrm{~h}$ followed by enzymatic hydrolysis and colorimetric detection of glucose (data not shown, Hall and Hatfield, 2015).

Organic Acids. Fermentations with glucose tended to have greater maximal amounts of lactate $(P=0.08)$ than did inulin and phlein, which did not differ $(P=$ 0.80; Table 2). Lactic acid accumulation $>0 \mu \mathrm{mol}$ was detected at $0.25 \mathrm{~h}$ in both fermentations for glucose, at 1.5 and $2 \mathrm{~h}$ for phlein, and at 3 and $4 \mathrm{~h}$ for inulin (data not shown). Thompson and Hobson (1971) reported

Table 3. Pearson correlation coefficients (and $P$-values) at detected maxima, with organic acid molar percentages calculated at the detected organic acid maxima in experiment 1

\begin{tabular}{|c|c|c|c|c|c|c|c|}
\hline Item & $\begin{array}{l}\text { Microbial } \\
\text { N, mg }\end{array}$ & $\begin{array}{c}\text { Lactate, } \\
\mu \mathrm{mol}\end{array}$ & $\begin{array}{l}\text { Organic acid } \\
\mathrm{C},{ }_{1} \mu \mathrm{mol}\end{array}$ & \multicolumn{4}{|c|}{ Molar percentages (mol\%) } \\
\hline Glycogen, mg & $\begin{array}{c}-0.546 \\
(0.26)\end{array}$ & $\begin{array}{c}0.582 \\
(0.23)\end{array}$ & $\begin{array}{r}-0.775 \\
(0.07)\end{array}$ & $\begin{array}{c}-0.773 \\
(0.07)\end{array}$ & $\begin{array}{c}0.456 \\
(0.36)\end{array}$ & $\begin{array}{c}0.489 \\
(0.32)\end{array}$ & $\begin{array}{c}0.333 \\
(0.52)\end{array}$ \\
\hline Microbial N, mg & & $\begin{array}{c}-0.679 \\
(0.14)\end{array}$ & $\begin{array}{c}0.384 \\
(0.45)\end{array}$ & $\begin{array}{r}0.637 \\
(0.17)\end{array}$ & $\begin{array}{c}-0.206 \\
(0.70)\end{array}$ & $\begin{array}{c}-0.539 \\
(0.27)\end{array}$ & $\begin{array}{c}-0.206 \\
(0.69)\end{array}$ \\
\hline Lactate, $\mu$ mol & & & $\begin{array}{c}-0.270 \\
(0.60)\end{array}$ & $\begin{array}{c}-0.808 \\
(0.05)\end{array}$ & $\begin{array}{r}0.230 \\
(0.66)\end{array}$ & $\begin{array}{c}0.549 \\
(0.26)\end{array}$ & $\begin{array}{c}0.846 \\
(0.03)\end{array}$ \\
\hline Acetate, $\mathrm{mol} \%$ & & & & & $\begin{array}{c}-0.365 \\
(0.48)\end{array}$ & $\begin{array}{c}-0.752 \\
(0.08)\end{array}$ & $\begin{array}{c}-0.526 \\
(0.28)\end{array}$ \\
\hline Propionate, $\mathrm{mol} \%$ & & & & & & $\begin{array}{r}-0.306 \\
(0.56)\end{array}$ & $\begin{array}{l}0.152 \\
(0.77)\end{array}$ \\
\hline Butyrate, mol\% & & & & & & & $\begin{array}{l}0.240 \\
(0.65)\end{array}$ \\
\hline
\end{tabular}

${ }^{1}$ Organic acids $=$ acetate + propionate + butyrate + valerate + lactate. 
substantial accumulation of both lactate and glycogen by ruminal microbes when given glucose, fructose, or sucrose as substrates. Considerably less or no lactate accumulated with xylose, galacturonic acid, cellobiose, maltose, or starch in that study. Thomas (1960) reported detecting lactic acid in fermentations of grass fructan beginning at $4 \mathrm{~h}$ of fermentation and greater accumulation with inoculum from a defaunated sheep than with protozoa present. A possible explanation for simultaneous lactate and glycogen accumulation noted in the present study and that of Thompson and Hobson (1971) is the need for ATP to support rapid glycogen synthesis. In addition to the 1 ATP cost to transport a glucose molecule into the cell, glycogen synthesis requires 1 ATP per glucose that is incorporated (Stouthamer, 1973). Lactate production, although less efficient in yield of ATP, occurs when flux is increased through the glycolytic pathway and could rapidly provide ATP for glycogen synthesis (Counotte and Prins, 1981; Russell and Hino, 1985). No lactate (minimum detectable limit $\sim 0.03 \mathrm{mM}$ ) was detected at $8 \mathrm{~h}$ of fermentation where maximum organic acid production was evaluated.

The maximum organic acid production expressed on a $\mathrm{C}$ basis was detected at $8 \mathrm{~h}$ of fermentation for all substrates. The maximum tended to be greater with fructans than with glucose $(P=0.08$; Table 2 , Figure $2 c)$. The fructan substrates, which are polysaccharides, contained approximately $11 \%$ more free hexose by weight than glucose, a monosaccharide. This is based on the weight of free monosaccharide expected upon hydrolysis of the polysaccharides due to the addition of the weight of 1 molecule of water per anhydro sugar bound within the molecules. However, the difference between glucose and the fructans slightly exceeded this expected difference. The difference in amount of organic acids produced may relate not just to disappearance of the purified substrates provided, but also to fermentation of the glycogen accumulated by cells and $\alpha$-glucan introduced with the inoculum. As shown in Figure 2b, at $8 \mathrm{~h}$ of fermentation, the fermentations with glucose contained approximately $4 \mathrm{mg}$ more $\alpha$-glucan than the fructan fermentations. The net additional fermented $\alpha$-glucan would contribute to the organic acids produced in the fructan fermentations.

Among the molar proportions of organic acids at the maxima, only acetate was affected by substrate (Table 2 ). The acetate molar percentage was less with glucose than with fructans $(P=0.02)$, and greater for inulin than for phlein $(P=0.03)$. It also tended to be negatively correlated with maximum lactate $(P=0.05$; Table 3$)$. The molar proportion of valerate was highly correlated with maximum lactate production $(P=$
0.03 ; Table 3). This may reflect lactate fermentation by the bacterium Megasphaera elsdenii, which efficiently converts lactate to valerate via propionate (Hino and Kuroda, 1993) and is known to preferentially increase in relative population size under in vitro conditions (Weimer et al., 2011). Except for valerate, molar proportions of acetate, propionate, butyrate, and valerate obtained in the present study were numerically similar to those detected at $72 \mathrm{~h}$ of fermentation with mixed ruminal microbes $(0.40,0.40,0.15$, and 0.06 , respectively; Weimer, 2011).

Rates of appearance of $\mathrm{C}$ in organic acids tended to be greater for phlein than for inulin $(P=0.11)$; glucose and phlein had numerically identical rates (Table 1 ). The lag time for appearance of organic acids tended to be shorter for glucose than for the fructans $(P=0.08)$, which did not differ $(P=0.31)$. The pattern across substrates for rates of organic acid production was numerically similar to that of substrate disappearance (Table 1). The difference in the magnitudes of the lags for substrate disappearance $(0.04 \mathrm{~h})$ and organic acid appearance $(0.45 \mathrm{~h})$ for glucose may be due to the substantial accumulation of glycogen with this substrate early in the fermentation.

Microbial Nitrogen/Cell Growth. Microbial cells represent a valuable source of AA for the cow. Differences among carbohydrates in their yields of microbes could be an important consideration in diet formulations to efficiently meet herd nutrient requirements. In the present study, rates of net microbial $\mathrm{N}$ accumulation (net microbial growth) were greater for glucose than for fructans $(P<0.01)$ and greater for phlein than for inulin $(P=0.03$; Table 1 , Figure $2 \mathrm{~d})$. Numerically, the rates of $\mathrm{N}$ accumulation appear to follow a similar pattern across substrates to those of substrate disappearance rates. Lag times for $\mathrm{N}$ accumulations were not detected as different among substrates $(P=$ 0.31). Despite having the highest rate of microbial $\mathrm{N}$ accumulation, glucose tended to have the lowest maximum amount of microbial $\mathrm{N}(P=0.08)$, whereas inulin and phlein did not differ from each other $(P=0.96)$. Although no significant relationship was found with glycogen $(P=0.26)$, the maximum $\mathrm{N}$ accumulation tended to be negatively correlated with the maximum amount of lactate $(P=0.14$; Table 3$)$. The relationship over time between $\mathrm{C}$ accumulated in cells divided by $\mathrm{C}$ in organic acids tended to show an effect of substrate, with a value of 0.69 for glucose, 0.86 for inulin, and 0.90 for phlein $(P=0.18$, standard error of the difference $=$ 0.16 ; glucose vs. fructans, $P=0.07$; inulin vs. phlein, $P=0.81$; overall effect of sampling hour, $P=0.43$; effect of hour $\times$ substrate, $P=0.59$ ). The lesser yield of cell $\mathrm{C}$ per amount of organic acid $\mathrm{C}$ with glucose 
may be a consequence of production of greater amounts of lactate and glycogen. The ATP cost of glycogen synthesis (Stouthamer, 1973), and lower yield of ATP from fermentations producing lactate as compared with other VFA (Russell and Wallace, 1988) could combine to leave less ATP available for cell growth with glucose than with the other hexose fermentations. A greater yield of microbes might have been expected from glucose due to proportionally less ATP being spent on maintenance at the higher growth rate (Isaacson et al., 1975). Thus, the greater efficiency resulting from rapid rate of growth with glucose may have partially overcome the ATP inefficiencies associated with glycogen and lactate production.

Efficiencies at Cell $\mathbf{N}$ Maxima. It can be challenging to accurately determine efficiencies of microbial product yield in mixed cultures, particularly for cell growth. A first challenge is determining the amount of substrate converted to microbial products. Although disappearance of added carbohydrate substrate is measured, other components in the fermentation can also contribute substrate: AA and peptides in medium, $\alpha$-glucan, carbohydrate, and protein in the medium. Theoretically, the organic acids produced in fermentation blanks should account for fermentation of substrate introduced with the inoculum and medium. This approach requires the assumption that all substrate introduced with inoculum did not make a net contribution to cell growth in the growing cul- tures provided with substrate as compared with the fermentation blanks; this is unlikely (Hall and Weimer, 2007). Additionally, in the present study, substrates differed in amounts of $\alpha$-glucan remaining after glycogen produced in the fermentations was degraded (after 4 h; Figure 2b), and a tendency was observed for differences between glucose and the fructans in the amount of $\alpha$-glucan used at the time of maximum microbial $\mathrm{N}$ accumulation. Combined, these findings suggest that current approaches to estimating substrates available for microbial growth as those added to the culture as a treatment are not adequate. The $\alpha$-glucan content of a culture can be measured and may be useful to account for more of the fermented carbohydrate. Correction for microbial use of $\mathrm{C}$ from proteinaceous sources or from very finely particulate fiber sources may be more difficult. In the present study, it was decided to add the consumed $\alpha$-glucan introduced with the inoculum to the amount of purified substrate consumed to estimate total utilized carbohydrate for calculation of efficiency of cell $\mathrm{C}$ yield.

No differences were detected in efficiencies of microbial product yield at maximal $\mathrm{N}$ accumulation (Table 4). Yields of $\mathrm{C}$ in organic acids and gases were numerically greater by approximately 7 and $12 \%$, respectively, for the fructans than for glucose, but these differences were not significant $(P>0.21)$. No difference was found among substrates in the amount of purified substrate that had been consumed $(P>0.22)$, but fermenta-

Table 4. Amounts of microbial product $\mathrm{C}$ and efficiency of product yield at the time of detected maximum microbial $\mathrm{N}$ accumulation in experiment 1

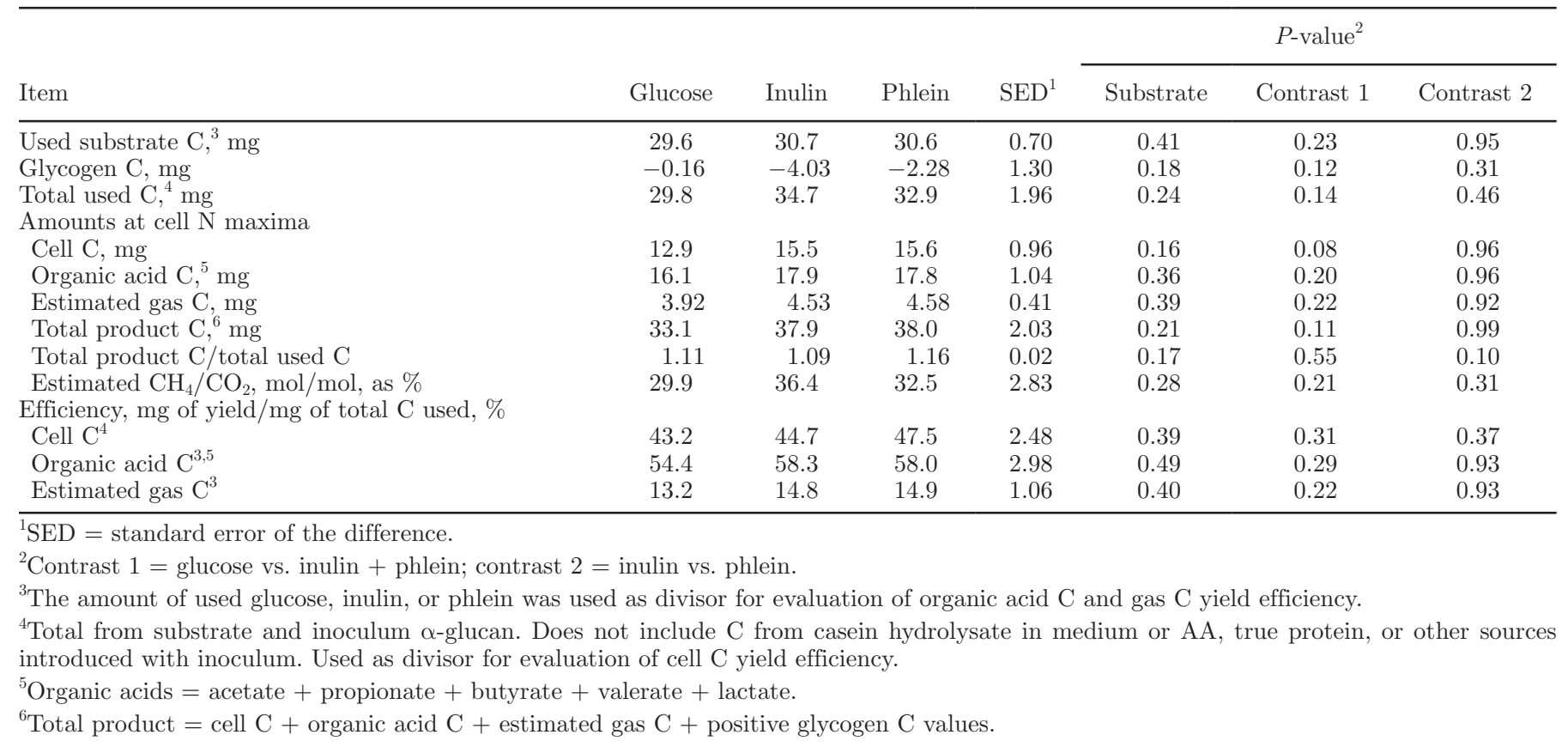


tions with glucose tended to consume less introduced $\alpha$-glucan by the time of maximal $\mathrm{N}$ accumulation than did the fructans $(P=0.12)$.

Observations on Early Hours of the Fermentation. Graphs of the first $2 \mathrm{~h}$ of fermentation may give insights into the interplay of microbial product formation and substrate disappearance (Figure 3). For glucose, it appears that both microbial $\mathrm{C}$ accumulation and VFA C appearance increased their rates near the 1-h point, where glycogen accumulation began to level out. As described in the analysis of cell $\mathrm{C} /$ organic acid $\mathrm{C}$, the lower value for glucose becomes marked after 1 $\mathrm{h}$, as well, with $\mathrm{C}$ in VFA exceeding that in microbial cells. For phlein and inulin, VFA and cell $\mathrm{C}$ appeared to rapidly increase at the point after lag where substrate began to decline appreciably. Unlike glucose, the lines for $\mathrm{C}$ in VFA and microbial cells largely overlay each other, and appreciable glycogen accumulation occurred after rates of cell and VFA formation increased. For inulin and phlein, these results suggest that it was not lack of availability of substrate that limited glycogen production, but differences in how microbes process the substrates. The amount of $\mathrm{N}$ from ammonia, AA, and peptides in the medium exceeded the yield of accumulated cell N, making it unlikely, though not verified, that the glucose cultures were not limited by the availability of $\mathrm{N}$.

\section{Experiment 2. Fermentations by Pure Cultures}

Pure cultures of 11 strains of ruminal bacteria tested fermented glucose, fructose, maltose, and sucrose (Table 5). Although growth rates on these substrates varied substantially (Table 5), only relatively minor differences were found in growth rates on glucose, fructose, and sucrose within a particular bacterial strain. For all species except B. fibrosolvens, L. plantarum, and $R$. amylophilus, growth rate on maltose was 14 to $48 \%$ slower than on the other 3 soluble sugars (mean: $27.5 \%$ slower, SD: 12.6\%). Phlein was fermented by all species tested except for L. plantarum NCIMB40027, a silage isolate not typically regarded as an active member of the ruminal microbiota. For the other 10 species, growth rates on phlein were 19 to $68 \%$ slower than on fructose (mean: $44.2 \%$ slower, SD: 14.4\%). Excluding the results with L. plantarum, growth rates on phlein were 22 to $75 \%$ slower than on glucose (mean: $48.0 \%$ slower, SD: $14.9 \%$ ). The rates for $\mathrm{N}$ accumulation for the mixed cultures in experiment 1 also showed rates that were $43 \%$ slower for phlein than for glucose. It should be noted that, in separate initial tests in tube cultures, 3 cellulolytic bacterial strains (Fibrobacter succinogenes S85, Ruminococcus flavefaciens FD-1, and Ruminococ-
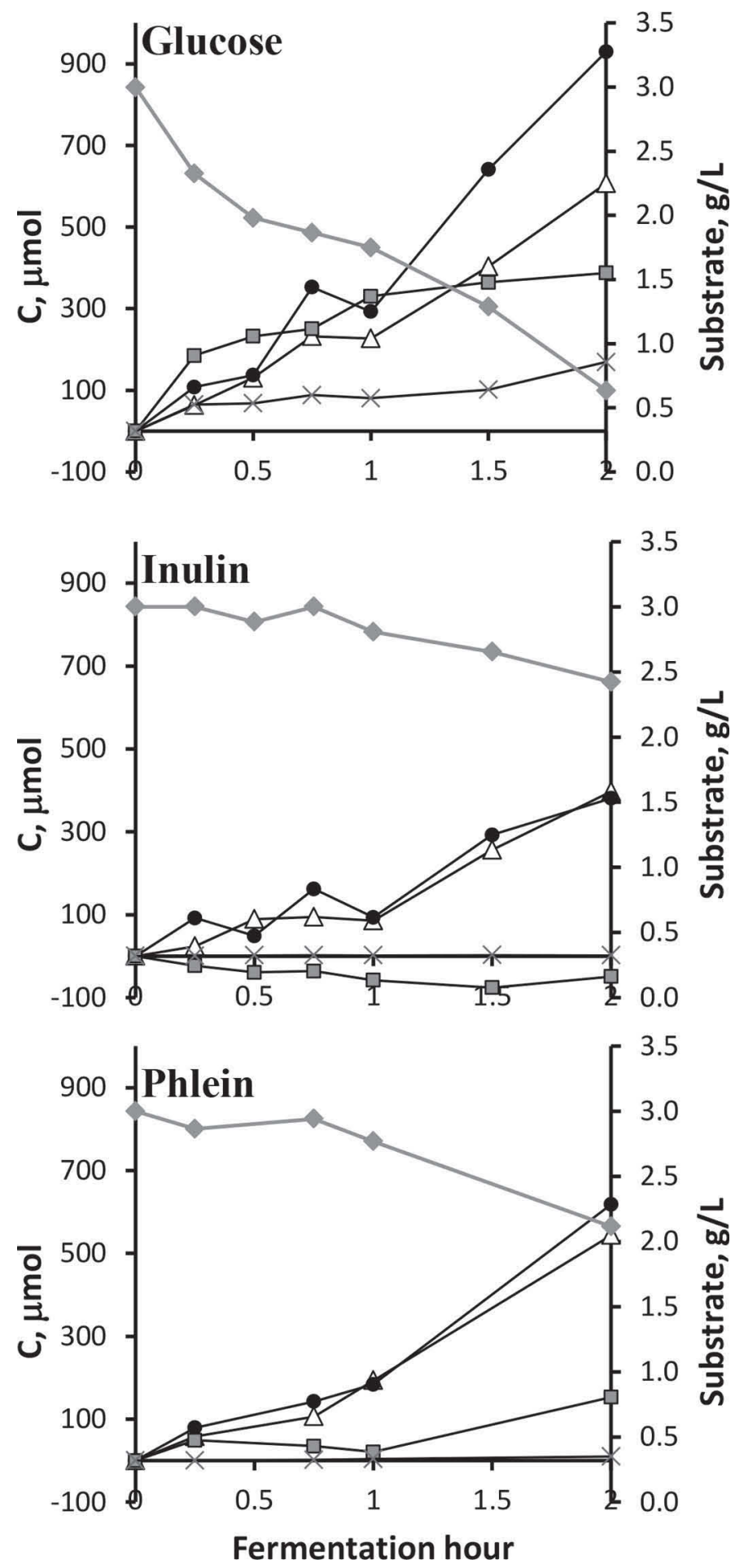

Figure 3. Patterns of substrate disappearance and microbial product appearance for glucose, phlein, and inulin substrates between 0 and $2 \mathrm{~h}$ of fermentation for mixed cultures (experiment 1). Substrate $=$ gray diamond, glycogen $=$ gray square, lactate $=\times$ symbol, microbial cells $=$ triangle, and VFA $=$ black circle. 
Table 5. Maximum specific growth rate constants $\left(\mu ; \mathrm{h}^{-1}\right)$ of pure cultures of ruminal bacteria grown on fructan and related sugars in experiment 2

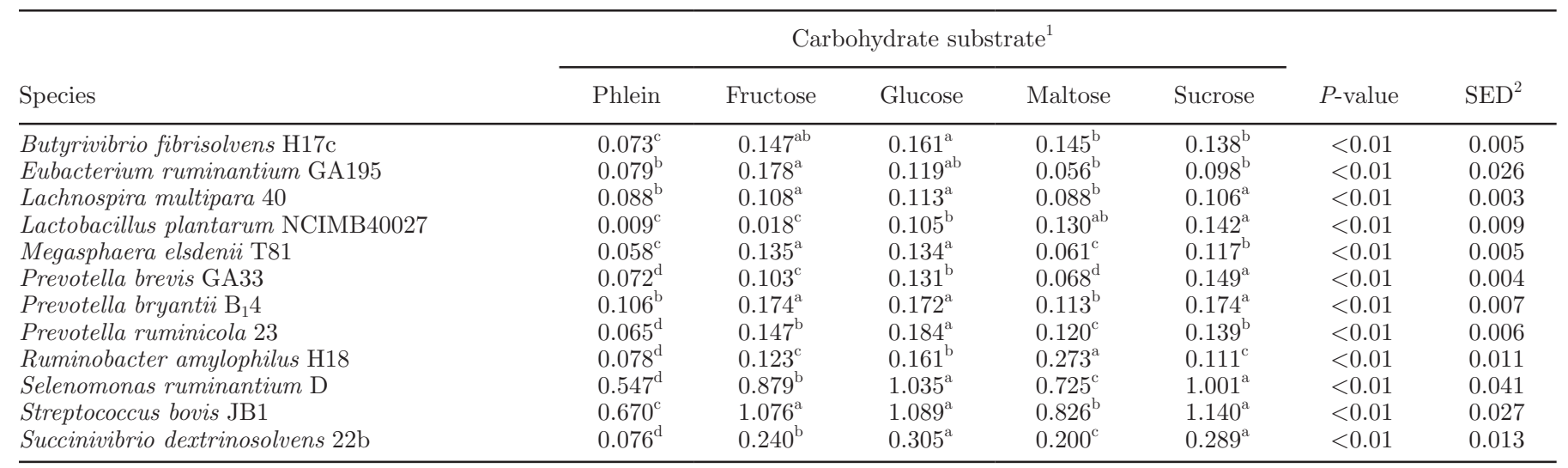

${ }^{\mathrm{a}-\mathrm{d}}$ Means with different superscripts within row differ $(P<0.05)$.

${ }^{1}$ Results are least squares means of 6 replicate cultures.

${ }^{2}$ Pooled standard error of the difference.

cus albus 7 ) did not ferment fructose, maltose, sucrose, or phlein (data not shown). Overall, it appears that the capability of fermenting phlein and other fructosyl compounds appears to be a general property of saccharolytic but noncellulolytic ruminal bacteria.

\section{CONCLUSIONS}

Glucose, chicory inulin, and grass phlein differed in their patterns of substrate disappearance and formation of microbial products with mixed ruminal microbes in vitro. With ruminal inoculum obtained from animals adapted to glucose, phlein, and the chicory inulin used in the study, phlein showed a greater accumulation of glycogen and a greater rate of microbial $\mathrm{N}$ accumulation than did inulin, while also tending toward a more rapid rate of organic acid production. This would suggest that inulin may not be an acceptable proxy for grass phlein in feeding studies. Although fructans are not digestible by mammalian enzymes, their degradation by saccharolytic, noncellulolytic ruminal bacteria suggests that grouping them with other plant WSC such as glucose, fructose, and sucrose may be acceptable if differences in rates and product formation can be taken into account.

\section{ACKNOWLEDGMENTS}

This research was supported with funding from USDA-Agricultural Research Service (ARS). Special thanks go to J. W. Pitas and C. L. Odt of the USDAARS US Dairy Forage Research Center, Madison, Wisconsin, for analytical assistance.

\section{REFERENCES}

Becker, J. U. 1978. A method for glycogen determination in whole yeast cells. Anal. Biochem. 86:56-64.

Biggs, D. R., and K. R. Hancock. 1998. In vitro digestion of bacterial and plant fructans and effects on ammonia accumulation in cow and sheep rumen fluids. J. Gen. Appl. Microbiol. 44:166-171.

Chen, G. J., and J. B. Russell. 1988. Fermentation of peptides and amino acids by a monensin-sensitive ruminal peptostreptococcus. Appl. Environ. Microbiol. 54:2742-2749.

Counotte, G. H. M., and R. A. Prins. 1981. Regulation of lactate metabolism in the rumen. Vet. Res. Commun. 5:101-115.

Czerkawski, J. W., and J. Lumsden. 1971. Invertase activity in the rumen contents of sheep given molassed sugar-beet pulp. Proc. Nutr. Soc. 30:53A-54A.

Daniels, L., R. S. Hanson, and J. A. Phillips. 2007. Chapter 18. Chemical analysis, Section 18.3.4. Glycogen. Page 469 in Methods of General and Molecular Bacteriology. 3rd ed. C. A. Reddy, ed. American Society for Microbiology, Washington, DC.

Dubois, M., K. A. Gilles, J. K. Hamilton, P. A. Rebers, and F. Smith. 1956. Colorimetric method for determination of sugars and related substances. Anal. Chem. 28:350-356.

Ernst, M. K., N. J. Chatterton, P. A. Harrison, and G. Matitschka. 1998. Characterization of fructan oligomers from species of the genus Allium L. J. Plant Physiol. 153:53-60.

Goering, H. K., and P. J. Van Soest. 1970. Forage fiber analysis (apparatus, reagents, procedures and some applications). Agriculture Handbook No. 379. ARS-USDA, Washington, DC.

Hackmann, T. J., B. L. Keyser, and J. L. Firkins. 2013. Evaluation of methods to detect changes in reserve carbohydrate for mixed rumen microbes. J. Microbiol. Methods 93:284-291.

Hall, M. B. 2011. Isotrichid protozoa influence conversion of glucose to glycogen and other microbial products. J. Dairy Sci. 94:4589-4602.

Hall, M. B., and R. D. Hatfield. 2015. Comparison of methods for glycogen analysis of in vitro fermentation pellets produced with strained ruminal inoculum. J. Microbiol. Methods 118:147-151. http://dx.doi.org/10.1016/j.mimet.2015.09.008.

Hall, M. B., and P. J. Weimer. 2007. Sucrose concentration alters fermentation kinetics, products, and carbon fates during in vitro fermentation with mixed ruminal microbes. J. Anim. Sci. 85:14671478.

Hendry, G. A. F., and R. K. Wallace. 1993. The origin, distribution, and evolutionary significance of fructans. Pages 119-139 in Science and Technology of Fructans, M. Suzuki and N. J. Chatterton, ed. CRC Press, Boca Raton, FL. 
Herbert, D., P. J. Phipps, and R. E. Strange. 1971. Chapter III. Chemical Analysis of Microbial Cells. Page 247 in Methods in Microbiology. Vol. 5B. J. R. Norris and D. W. Ribbons, ed. Academic Press Inc., London, UK.

Hino, T., and S. Kuroda. 1993. Presence of lactate dehydrogenase and lactate racemase in Megasphera elsdenii grown on glucose or lactate. Appl. Environ. Microbiol. 59:255-259.

Hristov, A. N., J. K. Ropp, K. L. Grandeen, S. Abedi, R. P. Etter, A. Melgar, and A. E. Foley. 2005. Effect of carbohydrate source on ammonia utilization in lactating dairy cows. J. Anim. Sci. 83:408421.

Hungate, R. E. 1966. The Rumen and its Microbes. Academic Press, New York, NY.

Isaacson, H. R., F. C. Hinds, M. P. Bryant, and F. N. Owens. 1975. Efficiency of energy utilization by mixed rumen bacteria in continuous culture. J. Dairy Sci. 58:1645-1659.

Lewis, D. H. 1993. Nomenclature and diagrammatic representation of oligomeric fructans - A paper for discussion. New Phytol. 124:583594 .

Mackenzie, D. J., and C. B. Wylam. 1957. Analytical studies on the carbohydrates of grasses and clovers. VIII. Changes in carbohydrate composition during the growth of perennial rye-grass. J. Sci. Food Agric. 8:38-45.

Masson, F. M., and A. E. Oxford. 1951. The action of the ciliates of the sheep's rumen upon various water-soluble carbohydrates, including polysaccharides. J. Gen. Microbiol. 5:664-672.

Matheron, C., A.-M. Delort, G. Gaudet, E. Forano, and T. Liptaj. 1998. ${ }^{13} \mathrm{C}$ and ${ }^{1} \mathrm{H}$ nuclear magnetic resonance study of glycogen futile cycling in strains of the genus Fibrobacter. Appl. Environ. Microbiol. 64:74-81.

NRC. 2001. Nutrient Requirements of Dairy Cattle. 7th rev. ed. Natl. Acad. Press, Washington, DC.

Pavlostathis, S. G., T. L. Miller, and M. J. Wolin. 1988. Fermentation of insoluble cellulose by continuous cultures of Ruminococcus albus. Appl. Environ. Microbiol. 54:2655-2659.

Piknova, M., W. Guczynska, R. Miltko, P. Javorsky, A. Kapserowicz, T. Michalowski, and P. Pristas. 2008. Treponema zioleckii sp. nov., a novel fructan-utilizing species of rumen treponemes. FEMS Microbiol. Lett. 289:166-172.

Prins, R. A., and W. Van Hoven. 1977. Carbohydrate fermentation by the rumen ciliate Isotricha prostoma. Protistologica (Paris) 13:549-556.

Rorabacher, D. B. 1991. Statistical treatment for rejection of deviant values: critical values of Dixon's "Q" parameter and related subrange rations at the 95\% confidence level. Anal. Chem. 63:139-146.
Russell, J. B., and T. Hino. 1985. Regulation of lactate production in Streptococcus bovis: A spiraling effect that contributes to rumen acidosis. J. Dairy Sci. 68:1712-1721.

Russell, J. B., J. D. O'Connor, D. G. Fox, P. J. Van Soest, and C. J. Sniffen. 1992. A net carbohydrate and protein system for evaluating cattle diets: I. Ruminal fermentation. J. Anim. Sci. 70:35513561.

Russell, J. B., and R. J. Wallace. 1988. Energy yielding and consuming reactions. Pages 185-215 in The Rumen Microbial Ecosystem. P. N. Hobson, ed. Elsevier, Barking, UK.

Stouthamer, A. H. 1973. A theoretical study on the amount of ATP required for synthesis of microbial cell material. Antonie van Leeuwenhoek 39:545-565.

Thomas, G. J. 1960. Metabolism of the soluble carbohydrates of grasses in the rumen of the sheep. J. Agric. Sci. 54:360-372.

Thompson, J. K., and P. N. Hobson. 1971. Polysaccharide synthesis and degradation by rumen micro-organisms in vitro. J. Agric. Sci. Camb. 76:423-432.

Van Kessel, J. S., and J. B. Russell. 1997. The endogenous polysaccharide utilization rate of mixed ruminal bacteria and the effect of energy starvation on ruminal fermentation rates. J. Dairy Sci. 80:2442-2448

Weimer, P. J. 2011. End product yields from the extraruminal fermentation of various polysaccharide, protein and nucleic acid components of biofuels and feedstocks. Bioresour. Technol. 102:32543259.

Weimer, P. J., and S. A. Abrams. 2001. In vitro fermentation of polydextrose by bovine ruminal microorganisms. Anim. Feed Sci. Technol. 93:115-123.

Weimer, P. J., J. M. Hackney, H.-J. G. Jung, and R. D. Hatfield. 2000 Fermentation of a bacterial cellulose/xylan composite by mixed ruminal microflora: Implications for the role of polysaccharide matrix interactions in plant cell wall biodegradability. J. Agric. Food Chem. 48:1727-1733.

Weimer, P. J., Y. Shi, and C. L. Odt. 1991. A segmented gas-liquid delivery system for continuous culture of microorganisms on insoluble substrates and its use for growth of Ruminococcus flavefaciens on cellulose. Appl. Microbiol. Biotechnol. 36:178-183.

Weimer, P. J., D. M. Stevenson, D. R. Mertens, and M. B. Hall. 2011. Fiber digestion, VFA production, and microbial population changes during in vitro ruminal fermentations of mixed rations in the absence or presence of monensin. Anim. Feed Sci. Technol. 169:68-78.

Ziolecki, A., W. Guczynska, and M. Wojciechowicz. 1992. Some rumen bacteria degrading fructan. Lett. Appl. Microbiol. 15:244-247. 